\title{
Pronounced Elevation of Undercarboxylated Osteocalcin in Healthy Children
}

\author{
MARIEKE VAN SUMMEREN, LAVIENJA BRAAM, FLORENCE NOIRT, WIETSE KUIS, AND CEES VERMEER
}

\begin{abstract}
Department of Pediatric Immunology [M.S., W.K.], University Medical Centre Utrecht, 3584 EA Utrecht, The Netherlands; Department of Biochemistry [L.B., C.V.], University of Maastricht, 6200 MD Maastricht, The Netherlands; Danone Research Centre Daniel Carasso

[F.N.], Palaiseau Cedex, 91767 France
\end{abstract}

\begin{abstract}
The vitamin $\mathrm{K}$-dependent protein osteocalcin is thought to play an important role in bone metabolism. Osteocalcin contains glutamic acid (Gla) residues, which have a high affinity for calcium. Vitamin $\mathrm{K}$ acts as an indispensable cofactor for the formation of these residues. Inadequate dietary vitamin $\mathrm{K}$ intake results in the synthesis of undercarboxylated (i.e. inactive) osteocalcin (ucOC). In adults, low vitamin $\mathrm{K}$ status of bone is associated with low bone density and increased risk of osteoporotic fractures. Little is known about vitamin $\mathrm{K}$ status and bone health in children. We used a cross-sectional study design to compare the vitamin $\mathrm{K}$ status of bone in healthy children $(n=86)$ with that of adults $(n=30)$. In children, a marked elevation of the ratio of ucOC/carboxylated osteocalcin (cOC), indicative of a poor vitamin $\mathrm{K}$ status, was observed. This difference persisted after adjusting for age, gender, puberty, height, weight. Furthermore, a marked correlation between the bone markers for bone metabolism and ucOC and cOC was found in the children's group. These findings suggest a pronounced low vitamin $\mathrm{K}$ status of bone during growth. The question remains, however, whether children would benefit from higher vitamin $\mathrm{K}$ intake, for instance, by improved bone health or stronger bones. (Pediatr Res 61: 366-370, 2007)
\end{abstract}

$\mathrm{V}$

itamin $\mathrm{K}$ and vitamin $\mathrm{K}$-dependent proteins (also known as Gla proteins) are best known for their role in blood coagulation. However, Gla proteins are also involved in other physiologic processes (e.g. bone metabolism) $(1,2)$. Osteocalcin is a bone Gla protein and synthesized by osteoblasts (3). It constitutes approximately $20 \%$ of the noncollagenous protein found in human bone (4).

Vitamin $\mathrm{K}$ acts as a cofactor in the posttranslational carboxylation of all Gla proteins. In this process, glutamate residues are converted into $\gamma$-carboxyglutamate (Gla) (5). Gla residues have a high affinity for calcium, and their complex formation with calcium ions was demonstrated to be essential for the function of all Gla proteins currently known.

To adequately carboxylate osteocalcin, the osteoblast requires sufficient vitamin $\mathrm{K}(6)$. In case of vitamin $\mathrm{K}$ deficiency, ucOC will be produced. Bioavailable vitamin $\mathrm{K}$ is mainly derived from nutritional sources. The gut flora also pro-

Received May 11, 2006; accepted October 24, 2006.

Correspondence: Cees Vermeer, Ph.D., Department of Biochemistry, University of Maastricht, PO Box 616, 6200 MD, Maastricht, The Netherlands; e-mail: C.Vermeer@BIOCH.unimaas.nl

This study was supported by funding from Danone Research Centre Daniel Carasso (NU097, Palaiseau Cedex, France).

DOI: 10.1203/pdr.0b013e318030d0b1 duces vitamin $\mathrm{K}$, but at the site of synthesis (colon) its absorption is negligible $(7,8)$. The two most important forms of vitamin $\mathrm{K}$ are phylloquinone (vitamin $\mathrm{K}_{1}$ ) and the group of $\mathrm{K}_{2}$ vitamins (menaquinones). Dietary sources of phylloquinone are green vegetables (spinach, broccoli) and some plant oils (9). Menaquinones are found in meat and fermented foods like cheese (10). Hence, inadequate intake of vitamin K will lead to the production of undercarboxylated (i.e. inactive) Gla proteins.

Methods have been developed to distinguish between $\mathrm{cOC}$ and ucOC fractions of osteocalcin $(11,12)$. The ratio between ucOC and $\mathrm{cOC}$ (UCR) as well as circulating ucOC levels are used as indicators for the vitamin $\mathrm{K}$ status of bone $(2,13,14)$. The UCR is probably the most sensitive marker for bone vitamin K status (2). Serum vitamin K concentrations fluctuate with recent dietary vitamin $\mathrm{K}$ intake and are not reliable markers for tissue vitamin $\mathrm{K}$ status. In the healthy adult population, osteocalcin is carboxylated to a variable extent, suggesting that the dietary vitamin $\mathrm{K}$ intake is insufficient for full osteocalcin carboxylation (15). Markedly higher osteocalcin carboxylation is obtained by increased vitamin $\mathrm{K}$ intake (16).

The benefits of vitamin $\mathrm{K}$ on bone metabolism and the prevention of fractures are well described in the adult population (17-21). Little is known about the vitamin $\mathrm{K}$ status in growing bone such as in children. Both the metabolic activity and osteocalcin production (22) are high during bone development and skeletal growth, suggesting that also the vitamin $\mathrm{K}$ requirement of bone is high. During recent years, the dietary intake of vitamin $\mathrm{K}$ in children (23) has declined gradually. The combination of high requirement and low intake may lead to subclinical vitamin $\mathrm{K}$ deficiency in the rapidly growing bone. In a cohort of in 245 healthy girls (ages, 3-16 y), Kalkwarf et al. (24) recently reported a marked variation in the percentage of ucOC. In this study, better vitamin $\mathrm{K}$ status (expressed as \%ucOC) was associated with decreased bone turnover. Furthermore, no evident correlations were found between \%ucOC and dietary intake or serum levels of vitamin $\mathrm{K}_{1}$. This is consistent with the view that serum vitamin $\mathrm{K}$ is a marker for recent dietary vitamin $\mathrm{K}$ intake but not for tissue vitamin $\mathrm{K}$ status.

Abbreviations: BAP, bone alkaline phosphatase; cOC, carboxylated osteocalcin; NTX, N-telopeptide cross-links of collagen breakdown; ucOC, undercarboxylated osteocalcin; UCR, ratio between ucOC and cOC 
The aim of this study was to compare the vitamin $\mathrm{K}$ status of bone in healthy children and adults in a cross-sectional study design. In addition, we studied possible correlations of vitamin $\mathrm{K}$ status with the level of bone turnover markers in children (high bone metabolic activity) and in adults (stable bone metabolic activity).

\section{METHODS}

Study subjects. From October 2003 through January 2004, 86 healthy children (male and female) between 3 and $18 \mathrm{y}$ of age were recruited from a population of children undergoing minor surgery (e.g. strabismus correction, phimosis correction), and friends or relatives of visiting patients in the Wilhelmina Children's Hospital. The Department of Biochemistry, University of Maastricht, recruited 30 healthy adult volunteers (25-35 y of age) via small ads. Subjects were included if they were within normal ranges for body weight and height according to reference growth charts. Exclusion criteria were current or previous medical diseases such as metabolic, gastrointestinal, or endocrine disease; chronic degenerative diseases; current medication such as anticoagulants and corticosteroids; and vitamin concentrates or food supplements.

Data collection procedure. This study was approved by the Central Committee on Research Involving Human Subjects (CCMO, The Netherlands). Written informed consent was obtained from all adults, the parents of all children, and also from children when $12 \mathrm{y}$ of age or older.

General data elements. Body height and weight of all subjects were measured in a standardized manner without shoes and heavy clothing, to the nearest centimeter and $100 \mathrm{~g}$, respectively. From these values, the body mass index (BMI) was calculated. Information about medical history and current use of any medication was ascertained by a short interview. In children, the pubertal stage was determined by a short list of questions about the presence of menarche and breast development (in females) or genital development (in males), according to Tanner's sexual maturity scale (SMS). The groups were divided into three categories: prepuberty (prepubertal stage), puberty (pubertal stages II-IV), and end of puberty (pubertal stage V).

Assessment of vitamin K status and bone turnover markers. After blood sampling, all samples were frozen and kept at $-80^{\circ} \mathrm{C}$ until use.

In serum, two biochemical markers of bone turnover were measured. Bone alkaline phosphatase (BAP) (Hybritech, Belgium) was measured as marker of bone formation by radio immunoassay. As a marker of bone resorption, $\mathrm{N}$-telopeptide cross-links of collagen breakdown (NTX) (Ostex, Washington) were determined. Undercarboxylated and carboxylated fractions of osteocalcin (Takara, Japan) were used as indicators of vitamin K status and measured by enzyme-linked immunosorbent assay. The UCR is a sensitive indicator of the vitamin K status of bone $(2,13)$. Elevated levels of UCR are indicative of an inferior vitamin $\mathrm{K}$ status of bone.

Statistical analysis. Normality of distribution for all subjects was checked by histograms for all study parameters. Independent $t$ tests and analysis of variance were used for comparison of parameters between children and adults. A $\chi^{2}$ test was performed for the differences in gender between adults and children. Pearson's correlation tests were performed to investigate possible correlations between demographic variables, bone markers, and vitamin $\mathrm{K}$ parameters in all groups. Stepwise multivariate linear regression analysis for the difference between children and adults was performed, using ucOC, $\mathrm{cOC}$, and UCR dependent variables with adjustments for the confounders age, gender, puberty, height, and weight. The statistical tests were performed using a two-sided significance level of $5 \%$. A $p$ value $<0.05$ was considered to be statistically significant. SPSS Base 12.0.2 for Windows (SPSS Inc, Chicago, IL) was used for all analyses.

\section{RESULTS}

Subjects. Eighty-six children (37 males, 49 females) and 30 adults (14 males, 16 females) were included in the study. Baseline characteristics of the subjects are shown in Table 1. The groups of adults and children differed in age, height, and weight, as might be expected. In the children's group, boys and girls did not differ in age (mean: 10.06 versus $10.01 \mathrm{y} ; p=$ 0.958 ), weight (mean: 40.8 versus $40.2 \mathrm{~kg} ; p=0.889$ ), height (mean: 155.6 versus $150.8 \mathrm{~cm} ; p=0.324$ ), and pubertal stage
Table 1. Demographic and anthropometric data, bone markers, and vitamin $K$ parameters of children and adults

\begin{tabular}{lccr}
\hline & $\begin{array}{c}\text { Children } \\
(n=86)\end{array}$ & $\begin{array}{c}\text { Adults } \\
(n=30)\end{array}$ & $p$ \\
\hline Age, y & $10.0(4.0)$ & $28.9(3.5)$ & $<0.001$ \\
Gender, male:female & $37: 49(43: 49)$ & $14: 16(47: 53)$ & 0.729 \\
Weight, kg & $40.4(17.3,76)$ & $70.8(12.0,30)$ & $<0.001$ \\
Height, cm & $152.8(17.1,56)$ & $176.9(10.8,30)$ & $<0.001$ \\
Bone markers & & & \\
$\quad$ BAP, ng/mL & $170.0(131.4)$ & $20.2(7.5)$ & $<0.001$ \\
$\quad$ NTX, ng/mL & $89.8(38.9)$ & $15.3(2.5)$ & $<0.001$ \\
Vitamin K parameters & & & \\
$\quad$ ucOC, ng/mL & $31.3(23.8)$ & $3.6(2.5)$ & $<0.001$ \\
$\quad$ COC, ng/mL & $15.4(7.3)$ & $4.7(1.5)$ & $<0.001$ \\
UCR & $2.3(1.6)$ & $0.8(0.5)$ & $<0.001$ \\
\hline
\end{tabular}

Results are presented as mean (SD), except for gender: male:female in $n: n$ (\%:\%).

Differences between the total group of children and adults were compared applying an independent $t$ test.

$\mathrm{SD}$, standard deviation.

$(p=0.103)$. Furthermore, no differences in these variables between male and female in adults were present.

Bone turnover parameters. The levels of BAP and NTX were elevated in children compared with adults (Table 1). This is consistent with the higher metabolic activity in growing bone in children. No differences in bone markers were found between boys and girls (data not shown). Both BAP and NTX significantly increased during puberty and declined by the end of puberty (data not shown).

Vitamin $K$ status of bone. The levels of ucOC and $\mathrm{cOC}$ were elevated in children as well (Table 1). In addition, the UCR in children was significantly higher than in adults, suggesting a poor vitamin K status of growing bone. Figure 1 shows the variation of the ucOC and cOC levels in children compared with the adult group. No differences in vitamin $\mathrm{K}$ status were found between boys and girls: ucOC (mean: 36.5 versus $27.4 \mathrm{ng} / \mathrm{mL} ; p=0.082$ ), cOC (mean: 16.9 versus 14.3 $\mathrm{ng} / \mathrm{mL} ; p=0.110$ ), and the UCR (mean: 2.46 versus 2.11 ; $p=0.445$ ).

To investigate whether this apparent vitamin $\mathrm{K}$ deficiency was associated with certain stages of development, we subdivided the children according to age and pubertal stage (Table 2). In all age groups, the UCR was above the adult level. A
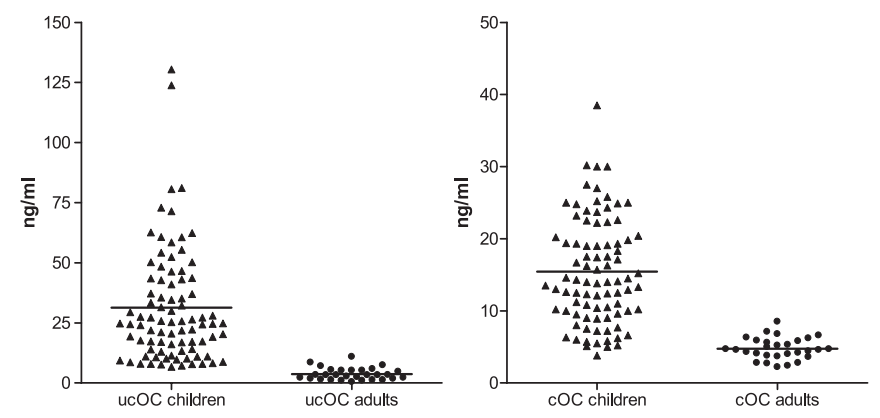
A B

Figure 1. Scatterplot of ucOC $(A)$ and $\mathrm{cOC}(B)$ in children $(n=86)$ and adults $(n=30)$. The $p$ value for the difference in the level of ucOC ( $t$ test) in children $v s$ adults is $<0.001(A)$. The $p$ value for the difference in the level of cOC ( $t$ test) in children $v s$ adults is $<0.001(B)$. 
Table 2. Vitamin K parameters in children of different age groups and pubertal stages

\begin{tabular}{|c|c|c|c|c|c|}
\hline & $n$ & $\mathrm{ucOC}(\mathrm{ng} / \mathrm{mL})$ & $p$ & UCR & $p$ \\
\hline \multicolumn{6}{|l|}{ Age groups } \\
\hline $3-8 y$ & 28 & $18.9(11.3)$ & 0.021 & $1.8(1.7)$ & $<0.001$ \\
\hline $8-13$ y & 33 & $40.2(25.2)$ & $<0.0001$ & $2.4(1.4)$ & $<0.001$ \\
\hline \multicolumn{6}{|l|}{ Pubertal stage } \\
\hline Prepubertal (Tanner I) & 55 & $26.8(16.9)$ & $<0.0001$ & $2.0(1.5)$ & 0.01 \\
\hline Puberty (Tanner II-IV) & 18 & $53.6(33.7)$ & $<0.0001$ & $2.6(1.7)$ & $<0.001$ \\
\hline
\end{tabular}

Vitamin K parameters (ucOC and UCR) in different subgroups of age and pubertal stage. Data are presented as mean (SD).

The $p$ value is in regard to the differences between the different subgroups of children (age groups and pubertal stage) and adults. Differences were compared applying an independent $t$ test.

Table 3. Differences in vitamin $K$ status between adults and children (multivariate analysis)

\begin{tabular}{|c|c|c|c|}
\hline & $\begin{array}{l}\Delta \text { Children } \\
\text { vs adults }\end{array}$ & $95 \% \mathrm{CI}$ & $p$ \\
\hline \multirow[t]{3}{*}{ ucOC (ng/mL) } & 27.7 & $18.9-36.5$ & $<0.001$ \\
\hline & 58.4 & $37.3-79.6$ & $<0.001 *$ \\
\hline & 32.7 & $4.9-60.5$ & $0.022 \dagger$ \\
\hline \multirow[t]{3}{*}{$\mathrm{cOC}(\mathrm{ng} / \mathrm{mL})$} & 10.7 & $8.0-13.4$ & $<0.001$ \\
\hline & 14.4 & $8.0-20.9$ & $<0.001 *$ \\
\hline & 5.6 & $2.1-13.3$ & $0.151 \dagger$ \\
\hline \multirow[t]{3}{*}{ UCR } & 1.5 & $0.9-2.1$ & $<0.001$ \\
\hline & 3.0 & $1.5-4.4$ & $<0.001 *$ \\
\hline & 2.5 & $0.8-4.2$ & $0.005 \dagger$ \\
\hline
\end{tabular}

Differences in vitamin $\mathrm{K}$ parameters (ucOC, cOC, and UCR) between the total group of children versus adults, adjusted for potential confounders.

Data are presented as difference $(\Delta)$ between children and adults, $95 \%$ CI (confidence interval) for the difference, and significance level of the difference $(p)$. Groups were compared applying a multivariate analysis adjusting for: * Age, gender, and puberty and †age, gender, puberty, height, and weight.

similar conclusion was obtained after subdivision according to pubertal stage. ucOC and cOC were highest during puberty and declined at the end of puberty. In postpubertal children, the cOC levels had almost reached adults values. Remarkably, the UCR remained high during all stages. Multiple linear regression analysis with adjustment for age, gender, and pubertal stage showed that ucOC, $\mathrm{COC}$, and the UCR in children were significantly higher than in adults (Table 3 ). When height and weight were also introduced in the equation, only ucOC and the UCR remained significantly different from the adult levels (Table 3).

Correlation of vitamin $K$ status and bone turnover parameters. In the total group of children, a marked correlation was found between the markers for bone metabolism (BAP and NTX) and both ucOC and cOC. The bone markers did not correlate with the UCR (Table 4). In adults, NTX, but not BAP, was correlated with the osteocalcin markers. In the total group (including adults and children), both BAP and NTX showed significant correlations with ucOC, $\mathrm{COC}$, and the UCR.

\section{DISCUSSION}

In this article, we report that high circulating levels of ucOC are found in the majority of children between 6 and $18 \mathrm{y}$ of age. Moreover, the UCR was significantly higher in children than in adults. These findings suggest a poor vitamin $\mathrm{K}$ status of bone during growth. The extent of vitamin K deficiency shows a substantially interindividual difference when considering the large variations in the UCR. In the elderly, high serum levels of ucOC have repeatedly been mentioned to be associated with low bone mass and high fracture risk. Whether children would benefit from increased dietary vitamin intake remains to be seen.

Osteocalcin is a vitamin $\mathrm{K}$-dependent protein almost exclusively synthesized by the osteoblasts in bone $(4,25)$. On a molecular level, its function is still obscure, but the circulating antigen is frequently used as a marker for osteoblast activity. One of the characteristics of vitamin $\mathrm{K}$-dependent proteins is that during episodes of low vitamin $\mathrm{K}$ intake, they are synthesized as undercarboxylated species. Osteocalcin is the only Gla protein known of which a relatively large fraction (20\%$30 \%$ ) circulates in an undercarboxylated form in healthy adults (15). The major part of newly synthesized osteocalcin is absorbed to the hydroxyapatite in bone, but a part of it leaks into the circulation where it can be detected (26).

The elevated levels of osteocalcin, BAP, and NTX in children, as found in the current study, are indicative of high metabolic activity in bone. Moreover, the high levels of ucOC

Table 4. Pearson correlation and significance level of relation between bone metabolic activity and the vitamin $K$ status in different groups

\begin{tabular}{lcccccc}
\hline Group & Children, $r$ & $p$ & Adults, $r$ & $p$ & Total group, $r$ \\
\hline BAP-ucOC & 0.435 & $<0.0001$ & 0.268 & 0.160 & 0.577 & 0.666 \\
BAP-cOC & 0.535 & $<0.0001$ & 0.136 & 0.481 & 0.111 & 0.251 \\
BAP-UCR & 0.051 & 0.641 & 0.303 & 0.001 & 0.650 & $<0001$ \\
NTX-ucOC & 0.481 & $<0.0001$ & 0.600 & 0.005 & 0.699 \\
NTX-cOC & 0.499 & $<0.0001$ & 0.505 & 0.038 & 0.374 \\
NTX-UCR & 0.123 & 0.258 & 0.387 & $<0001$ & $<0.0001$ \\
\hline
\end{tabular}

Correlation between bone markers (BAP, NTX) and vitamin K parameters (ucOC, cOC, UCR) in children, adults, and the total group (both adults and children). Data are presented as Pearson's correlation coefficient $(r)$ and significance level $(p)$. 
suggest that the vitamin $\mathrm{K}$ requirement of bone during growth is not met by the dietary vitamin $\mathrm{K}$ supply. It may be argued that high ucOC levels are representative for the high bone turnover state found in adolescence rather than the result of vitamin $\mathrm{K}$ deficiency. Indeed, the serum ucOC level is determined by both the total osteocalcin production and the fraction thereof that has been carboxylated by vitamin $\mathrm{K}$ action. Therefore, the UCR (or total OC), which is independent of bone turnover, is a more reliable marker for vitamin $\mathrm{K}$ status of the bone. In our study, we found very high UCR values in children compared with adults, suggesting subclinical vitamin $\mathrm{K}$ deficiency during high bone turnover in children. This is consistent with observations in another population characterized by high bone metabolism, i.e. postmenopausal women $(19,21,27,28)$. Several authors have demonstrated that, in the latter group, low dietary vitamin $\mathrm{K}$ intake, high circulating ucOC, and high UCR are associated with low bone mineral density and increased fracture risk. In these women, the serum ucOC levels are higher than in young adults.

From our study, it is clear that both the absolute concentration of ucOC and the UCR in children are much higher than in healthy adults or even in postmenopausal women. Here we postulate that the metabolic activity of bone is associated with its vitamin $\mathrm{K}$ requirement. Children during growth have a much higher bone metabolism than adults. This may be a possible explanation for the apparent vitamin $\mathrm{K}$ deficiency in children of all ages.

In children, the importance of vitamin $\mathrm{K}$ status in bone health has only been studied by a small number of research workers (29). Kalkwarf et al. (24) described that in healthy girls (3-16 y), greater vitamin $\mathrm{K}$ status was associated with decreased bone metabolic activity. Furthermore, in children with long-standing vitamin $\mathrm{K}$ deficiency caused by the anticoagulation drug warfarin, a reduced bone density was found (30). This study illustrates the potential consequences of vitamin $\mathrm{K}$ deficiency in growing bone.

However, the question still remains whether improved bone health in children can be achieved by higher vitamin $\mathrm{K}$ intake. The value of vitamin $\mathrm{K}$ supplements has been shown in several studies in postmenopausal women. In this group, vitamin $\mathrm{K}$ supplementation results in decreased bone loss (31) or even gain of bone mass (32-34). Besides an effect on bone mineral density, recent data suggest that the most important benefit of vitamin $\mathrm{K}$ in bone is improved geometry. In an article that has only been published as an abstract thus far, Kaptoge et al. showed that in elderly women vitamin $\mathrm{K}$ supplementation resulted in increased femur neck width and increased bone strength at this site (Kaptoge S, Dalzell N, Welch A, Shearer MJ, Khaw KT, Reeve J 2005 Vitamin K and fracture risk: an effect on bone not BMD? Bone and Tooth Society Annual Meeting, July 4-5, 2005, Birmingham, UK, Abstract No. 12). Recently, this was confirmed in galactosemic children (B. Panis et al., unpublished results), a group known to have low BMD.

Our report describes the finding of a possible vitamin $\mathrm{K}$ deficiency in bone. The major limitation of this study is that we were only able to link these results to markers of bone metabolism and not to assessment of bone mass or strength. The confirmation that this apparent deficiency may affect bone quality can only be established in prospective pediatric studies. Another limitation concerns the cross-sectional design of our study. Prospective studies in which possible changes in UCR are monitored in a time-dependent manner may demonstrate whether vitamin $\mathrm{K}$ status is fluctuating during different episodes of growth or whether it is consistently associated with young age.

Our finding that, based on osteocalcin carboxylation, most of the children in a healthy population must be defined as vitamin $\mathrm{K}$-deficient is a point of interest and justifies follow-up studies in which bone quality is monitored as a function of vitamin $\mathrm{K}$-intake.

Acknowledgments. The authors thank Kirsten Teunissen for her excellent work in laboratory analysis.

\section{REFERENCES}

1. Shearer MJ 2000 Role of vitamin K and Gla proteins in the pathophysiology of osteoporosis and vascular calcification. Curr Opin Clin Nutr Metab Care 3:433-438

2. Vermeer C, Shearer MJ, Zittermann A, Bolton-Smith C, Szulc P, Hodges S, Walter P, Rambeck W, Stocklin E, Weber P 2004 Beyond deficiency: potential benefits of increased intakes of vitamin $\mathrm{K}$ for bone and vascular health. Eur J Nutr 43:325-335

3. Price PA, Poser JW, Raman N 1976 Primary structure of the gammacarboxyglutamic acid-containing protein from bovine bone. Proc Natl Acad Sci U S A 73:3374-3375

4. Hauschka PV, Lian JB, Gallop PM 1975 Direct identification of the calcium-binding amino acid, gamma-carboxyglutamate, in mineralized tissue. Proc Natl Acad Sci U S A 72:3925-3929

5. Wallin R, Sane DC, Hutson SM 2002 Vitamin K 2,3-epoxide reductase and the vitamin K-dependent gamma-carboxylation system. Thromb Res 108:221-226

6. Koshihara Y, Hoshi K 1997 Vitamin K2 enhances osteocalcin accumulation in the extracellular matrix of human osteoblasts in vitro. J Bone Miner Res 12:431-438

7. Conly JM, Stein K 1992 The production of menaquinones (vitamin K2) by intestinal bacteria and their role in maintaining coagulation homeostasis. Prog Food Nutr Sci 16:307-343

8. Conly JM, Stein K 1992 Quantitative and qualitative measurements of K vitamins in human intestinal contents. Am J Gastroenterol 87:311-316

9. Bolton-Smith C, Price RJ, Fenton ST, Harrington DJ, Shearer MJ 2000 Compilation of a provisional UK database for the phylloquinone (vitamin K1) content of foods. Br J Nutr 83:389-399

10. Schurgers LJ, Vermeer C 2000 Determination of phylloquinone and menaquinones in food. Effect of food matrix on circulating vitamin $\mathrm{K}$ concentrations. Haemostasis 30:298-307

11. Gundberg CM, Nieman SD, Abrams S, Rosen H 1998 Vitamin K status and bone health: an analysis of methods for determination of undercarboxylated osteocalcin. J Clin Endocrinol Metab 83:3258-3266

12. Knapen MH, Eisenwiener HG, Vermeer C 1996 Osteocalcin detection in aging serum and whole blood: stability of different osteocalcin fractions. Clin Chim Acta 256:151-164

13. Sokoll LJ, Sadowski JA 1996 Comparison of biochemical indexes for assessing vitamin $\mathrm{K}$ nutritional status in a healthy adult population. Am J Clin Nutr 63:566-573

14. Sokoll LJ, Booth SL, O'Brien >ME, Davidson KW, Tsaioun KI, Sadowski JA 1997 Changes in serum osteocalcin, plasma phylloquinone, and urinary gammacarboxyglutamic acid in response to altered intakes of dietary phylloquinone in human subjects. Am J Clin Nutr 65:779-784

15. Binkley NC, Krueger DC, Engelke JA, Foley AL, Suttie JW 2000 Vitamin K supplementation reduces serum concentrations of under-gamma-carboxylated osteocalcin in healthy young and elderly adults. Am J Clin Nutr 72:1523-1528

16. Binkley NC, Krueger DC, Kawahara TN, Engelke JA, Chappell RJ, Suttie JW 2002 A high phylloquinone intake is required to achieve maximal osteocalcin gammacarboxylation. Am J Clin Nutr 76:1055-1060

17. Cockayne S, Adamson J, Lanham-New S, Shearer MJ, Gilbody S, Torgerson DJ 2006 Vitamin K and the prevention of fractures: systematic review and metaanalysis of randomized controlled trials. Arch Intern Med 166:1256-1261

18. Feskanich D, Weber P, Willett WC, Rockett H, Booth SL, Colditz GA 1999 Vitamin $\mathrm{K}$ intake and hip fractures in women: a prospective study. Am J Clin Nutr 69:74-79

19. Luukinen H, Kakonen SM, Pettersson K, Koski K, Laippala P, Lovgren T, Kivela SL, Vaananen HK 2000 Strong prediction of fractures among older adults by the ratio of carboxylated to total serum osteocalcin. J Bone Miner Res 15:2473-2478

20. Szulc P, Chapuy MC, Meunier PJ, Delmas PD 1996 Serum undercarboxylated osteocalcin is a marker of the risk of hip fracture: a three year follow-up study. Bone $18: 487-488$ 
21. Szulc P, Arlot M, Chapuy MC, Duboeuf F, Meunier PJ, Delmas PD 1994 Serum undercarboxylated osteocalcin correlates with hip bone mineral density in elderly women. J Bone Miner Res 9:1591-1595

22. Szulc P, Seeman E, Delmas PD 2000 Biochemical measurements of bone turnover in children and adolescents. Osteoporos Int 11:281-294

23. Prynne CJ, Thane CW, Prentice A, Wadsworth ME 2005 Intake and sources of phylloquinone (vitamin $\mathrm{K}(1)$ ) in 4-year-old British children: comparison between 1950 and the 1990s. Public Health Nutr 8:171-180

24. Kalkwarf HJ, Khoury JC, Bean J, Elliot JG 2004 Vitamin K, bone turnover, and bone mass in girls. Am J Clin Nutr 80:1075-1080

25. Beresford JN, Gallagher JA, Poser JW, Russell RG 1984 Production of osteocalcin by human bone cells in vitro. Effects of $1,25(\mathrm{OH}) 2 \mathrm{D} 3,24,25(\mathrm{OH}) 2 \mathrm{D} 3$, parathyroid hormone, and glucocorticoids. Metab Bone Dis Relat Res 5:229-234

26. Price PA, Williamson MK, Lothringer JW 1981 Origin of the vitamin K-dependent bone protein found in plasma and its clearance by kidney and bone. J Biol Chem 256:12760-12766

27. Knapen MH, Nieuwenhuijzen Kruseman AC, Wouters RS, Vermeer C 1998 Correlation of serum osteocalcin fractions with bone mineral density in women during the first 10 years after menopause. Calcif Tissue Int 63:375-379
28. Szulc P, Chapuy MC, Meunier PJ, Delmas PD 1993 Serum undercarboxylated osteocalcin is a marker of the risk of hip fracture in elderly women. J Clin Invest 91:1769-1774

29. Cashman KD 2005 Vitamin K status may be an important determinant of childhood bone health. Nutr Rev 63:284-289

30. Barnes C, Newall F, Ignjatovic V, Wong P, Cameron F, Jones G, Monagle P 2005 Reduced bone density in children on long-term warfarin. Pediatr Res 57:578-581

31. Braam LA, Knapen MH, Geusens P, Brouns F, Hamulyak K, Gerichhausen MJ, Vermeer C 2003 Vitamin K1 supplementation retards bone loss in postmenopausal women between 50 and 60 years of age. Calcif Tissue Int 73:21-26

32. Iwamoto J, Takeda T, Ichimura S 2003 Combined treatment with vitamin $\mathrm{K} 2$ and bisphosphonate in postmenopausal women with osteoporosis. Yonsei Med J 44:751-756

33. Shiraki M, Shiraki Y, Aoki C, Miura M 2000 Vitamin K2 (menatetrenone) effectively prevents fractures and sustains lumbar bone mineral density in osteoporosis. J Bone Miner Res 15:515-521

34. Ushiroyama T, Ikeda A, Ueki M 2002 Effect of continuous combined therapy with vitamin $\mathrm{K}(2)$ and vitamin $\mathrm{D}(3)$ on bone mineral density and coagulofibrinolysis function in postmenopausal women. Maturitas 41:211-221 